\title{
Tres procesos judiciales: hacia una estética del acontecimiento ${ }^{1}$
}

\author{
ÓSCAR NUDLER \\ CONICET, Fundación Bariloche
}

RESUMEN. Se formula el problema de trazar una analogía entre tres acontecimientos en principio difícilmente comparables entre si: los procesos de Sócrates, Galileo y Josef K. Se analizan las principales interpretaciones que se han dado de cada uno de ellos y se concluye que son insatisfactorias. Se propone un enfoque alternativo - una estética del acontecimiento-, el cual pone de manifiesto una analogía profunda entre los tres procesos. Se argumenta, en primer lugar, que los tres procesos han tenido como trasfondo una crisis de la articulación entre la imagen del mundo, la forma de vida y el sentido. $Y$, en segundo lugar, que los tres son modos arquetípicos de enfrentamiento entre el Poder y el individuo.

\section{Consideraciones introductorias}

La materia prima de este ensayo está constituida por tres acontecimientos, dos de ellos históricos y el tercero un producto de la ficción literaria: los procesos de Sócrates, Galileo y Josef K. ¿Por qué reunir en un mismo estudio episodios tan distantes y disímiles entre sí? Antes de responder hagamos una rápida reseña del desarrollo de nuestros tres casos:
ABSTRACT. The problem of drawing a significant analogy between three events at first sight hardly comparable is described, namely, the trials of Socrates, Galileo, and Joseph K. Some main interpretations are analyzed but all of them are found nor really satisfactory. An alternative approach is then introduced -an «esthetic of the event»- which discloses a deep analogy between the three trials. So it is argued, first, that in the background of all the three events a crisis of the articulation between the world image, the form of life, and meaning was developing. And, secondly, it is also argued that the three trials are archetypical modes of the clash between the individual and Power.

En el año 399 a. C. Sócrates fue acusado ante un tribunal formado por 500 miembros elegidos por sorteo entre los ciudadanos de Atenas. Los cargos contra Sócrates eran los de «corromper a los jóvenes y no creer en los dioses en que la ciudad cree sino en otras divinidades nuevas». Luego de oír el alegato acusatorio y la defensa hecha por el mismo acusado, el tribunal lo halló, por el yoto de la mayoría, culpable y, a continuación de una nueva intervención del acusado, lo condenó a muerte, esta vez por 
un margen mayor de votos. La sentencia se cumplió un mes después de pronunciada.

En el año 1633 de la era cristiana Galileo Galilei fue procesado por el tribunal del Santo Oficio en Roma. La acusación era que, desafiando la prohibición dispuesta por la Iglesia en 1616, Galileo había defendido las tesis copernicanas de que kel sol está en el centro del mundo y es inmóvil y que la tierra no es inmóvil ni está en el centro del mundo sino que se mueve como un todo $\mathrm{y}$ también con un movimiento diurno". Luego de intentar defenderse, el acusado reconoció su culpa ante sus jueces y leyó públicamente una declaración de arrepentimiento y abjuración de aquellas tesis. Fue condenado a prisión por el tiempo que el tribunal estimara conveniente (el cual fue de hecho hasta su muerte), a no tener contactos con extraños y a recitar salmos de penitencia todos los días durante tres años.

En época y lugar no precisados, Josef K. fue visitado una mañana en la pensión en que vivía por tres agentes que le comunicaron que estaba detenido. Ni los cargos que supuestamente pesaban sobre él ni el tribunal que lo juzgaba le fueron informados. No obstante su arresto, Josef $\mathbf{K}$. fue autorizado a proseguir con sus actividades habituales mientras se sustanciaba el proceso. $K$. intentó diversos modos de liberarse de esa incómoda situación pero nunca pudo siquiera acceder al tribunal que supuestamente lo juzgaba para defenderse ni averiguar en qué estado se encontraba su proceso. Finalmente, al cumplirse un año del inicio del proceso, fue ejecutado por dos verdugos, ejecución que, a esa altura, $K$. aceptó con resignación.

Retomemos ahora el interrogante planteado al inicio acerca de cómo justificar la reunión en un mismo estudio de tres episodios tan dispares entre sí. La respuesta es que los tres ofrecen, más allá de las diferencias entre sus protagonistas, entre los tribunales que intervinieron, entre los procedimientos judiciales que se siguieron en cada caso, entre los respectivos contextos, etc., la posibilidad de trazar una cierta analogía profunda e iluminadora entre ellos. A fin de aclarar la naturaleza de esta analogía, miremos a nuestros episodios desde un ángulo estético, como si fueran piezas de teatro trágico. Siguiendo esta metáfora teatral, lo primero que impacta es la extraordinaria capacidad mimética, en el sentido aristotélico del término, de nuestras tres «tragedias». Recordemos que el Estagirita caracteriza a la tragedia como una «imitación» (mímesis) de una acción (Poética, cap. VII). La mímesis propia de la poesía trágica (a diferencia de la crónica histórica) no es según Aristóteles una mera copia de acciones o hechos que sucedieron, sino un modo de capturar lo que hay de universal en ellos. De ahí su célebre dictum de que la poesía es más filosófica que la historia.

Adoptando, pues, esta visión estética aristotélica de nuestros acontecimientos, debemos preguntarnos por el universal al que nos remite cada una de estas tragedias. Según argumentaré más adelante, las tres - y no importa desde un punto de vista filosófico si refieren sucesos que efectivamente sucedieron o sucesos que han sido creados por la imaginación de un artistaremiten a ciertos modos arquetípicos de choque entre el Poder y el individuo. Una característica en común de estos choques es que se dan en el contexto, o sobre el trasfondo, de una crisis generalizada o global de una forma de orden. En nuestros ejemplos, la crisis de la polis antigua, la crisis del orden medieval, la crisis de la modernidad, respectivamente. Así pues, del mismo modo en que el Hamlet de Shakespeare «imita» o muestra (en el sentido wittgensteiniano) «lo podrido en Dinamarca», nuestros tres procesos «imitarían» la descomposición de un orden y el destino trágico de un individuo atrapado por él.

Ahora bien, si echamos aunque no sea más que una rápida ojeada a la inmensa literatura disponible en torno de cada uno de nuestros episodios, resulta evidente que las interpretaciones predominantes de cada uno de ellos no asumen una mirada estética como la recién mencionada sino una lógica causal. Estas interpretaciones pre- 
tenden revelarnos la causa decisiva o determinante del procesamiento y condena de nuestros personajes. Lo llamativo es que en ninguno de los tres casos se ha alcanzado dentro de las respectivas comunidades de estudiosos un grado apreciable de consenso en torno de la supuesta causa, y ello a pesar de la extraordinaria erudición y fineza de análisis que exhiben algunas de las interpretaciones ofrecidas. Subsiste, por el contrario, la prolongada e intensa lucha no resuelta de interpretaciones alternativas. A continuación, luego de describir concisamente en el próximo apartado esa lucha de interpretaciones en cada uno de nuestros casos, retomaré en el siguiente su lectura desde una estética del acontecimiento

\section{Una lucha de interpretaciones}

Dada la imposibilidad, por razones de espacio, de mencionar siquiera las distintas cuestiones en torno de las cuales se ha desplegado esta lucha de interpretaciones, me ceñiré a una sola de ellas: ¿cuál fue el delito o crimen que, según quienes los juzgaron, habrían cometido nuestros personajes?

Comencemos por la acusación a Sócrates y veamos las dos interpretaciones alternativas principales acerca de su naturaleza. La acusación formal, expuesta por Meleto, estaba dividida como vimos en tres partes: no creer en los dioses en que la ciudad cree, introducir nuevas divinidades y corromper a la juventud. En su discurso de defensa, al menos según nos lo trasmitió Platón en la Apología ${ }^{2}$, Sócrates argumenta que estas acusaciones no eran en realidad las verdaderas acusaciones ya que había otras, no formuladas, más antiguas y más peligrosas para él porque estaban arraigadas desde hacía mucho tiempo en la mente de los atenienses y, por tanto, de los miembros del jurado. Sócrates formula esas antiguas acusaciones de la siguiente manera:
Sócrates es culpable de indagar acerca de cosas en el cielo y que se encuentran debajo de la tierra, y de hacer pasar por más fuerte el argumento más débil, y enseñar a otros estas mismas cosas (Apología, 18 b6-cl).

Tanto aquí como en la acusación formal está presente el cargo de impiedad —asébeia-, es decir, una imputación de carácter religioso. Sin embargo, la acusación «antigua» es en principio más grave, ya que no es de heterodoxia, según parece razonable interpretar el cargo de Meleto, sino de ateísmo, dada la identificación que se hace de Sócrates como phisiologoi, o sea, como filósofo natural (el que indaga acerca de cosas en el cielo y debajo de la tierra), y como sofista (el que hace pasar el argumento débil por fuerte), ocupaciones ambas popularmente asociadas con el ateísmo. Se ha especulado por qué Sócrates mismo introdujo en su defensa esta interpretación más peligrosa de la acusación religiosa. La respuesta es generalmente que le era más fácil demostrar su falsedad. Ahora bien, a la lectura literal de la acusación principal en contra de Sócrates como una acusación de carácter religioso, una larga tradición, que comienza ya con Jenofonte y que llega hasta nuestros días ${ }^{3}$, le contrapone la tesis de que la verdadera acusación, no formulada explícitamente, era de carácter político. Que Sócrates no haya sido formalmente acusado de un crimen político es explicado sobre la base de que lo impedía la amnistía decretada después de la caída de la dictadura de los Treinta Tiranos impuesta por Esparta, pocos años antes del proceso. Los argumentos a favor de esta manera de interpretar el enjuiciamiento y condena de Sócrates son múltiples. Para empezar, se recuerda la existencia de discípulos de Sócrates que fueron notorios enemigos de la democracia, en particular Critias, tío de Platón, nada menos que uno de los miembros de la dictadura oligárquica de los Treinta. Y están sobre todo las críticas 
explícitas hechas por Sócrates a procedimientos de la democracia ateniense, en especial la elección de jurados por sorteo, y su preferencia por gobernantes y jueces que accedan a la función exclusivamente en base a un conocimiento o tejné específica. A ello se agrega la renuncia de Sócrates a participar de la actividad políti$\mathrm{ca}$, en especial de la Asamblea, participación que Pericles ${ }^{4}$ había calificado como definitoria no sólo de la condición de ciudadano, sino también de la misma condición de hombre. En verdad, lo que Sócrates plantea en la Apología es una incompatibilidad entre la forma de vida filosófica y la política, tal como era entendida y practicada en Atenas. Había, pues, motivos más que sobrados para que el partido democrático dominante estuviera predispuesto en contra de Sócrates.

Con todo, la interpretación política del delito imputado a Sócrates está lejos de poder ser considerada sin más como la causa de su procesamiento y condena. Por un lado, junto a discípulos simpatizantes de la oligarquía, Sócrates tuvo también discípulos que fueron líderes democráticos, como fue el caso de Querofonte. Pero aun si no los hubiera tenido, no podía acusarse a Sócrates de delitos cometidos por otros, aunque hubieran sido discípulos suyos. Por otra parte, Sócrates siempre se mantuvo leal a la democrática Atenas en las guerras contra sus enemigos y, lejos de alinearse en su momento con la dictadura, había arriesgado su vida al negarse a obedecer una orden de participar en la captura y ejecución de un opositor. Así pues, si bien la dimensión política debe haber jugado un papel importante, no parece haber una base suficiente como para considerarla tan decisiva como los defensores de esta interpretación pretenden.

Regresemos, pues, a la interpretación religiosa 5 . No le faltan, al igual que a la interpretación política, evidencias de diverso tipo en su favor. Por una parte, tenemos la creencia socrática en una divi- nidad o daimon privado que según Sócrates le hablaba al oído para disuadirlo de tomar ciertos cursos de acción (a esto parece referirse la acusación de introducir nuevas divinidades). $Y$, por otra parte, estaba su concepción racionalista y moralista de los dioses, opuesta a la de los dioses demasiado humanos de la religión oficial, movidos por celos, envidias, afán de venganza o pura búsqueda hedonista de placeres. Es claro que para un ciudadano ateniense promedio, y más aún para un fanático religioso como Anito, el más importante de sus acusadores, todo esto debía ser muy poco aceptable. Sin embargo, Sócrates no era ciertamente un agnóstico al estilo de Protágoras y otros intelectuales, sino un hombre piadoso. No sólo creía en la existencia de los dioses, sino que también seguía las prácticas de los ritos oficiales. Por ende, la interpretación religiosa del procesamiento y condena de Sócrates tampoco parece tener títulos suficientes como para arrogarse el carácter de causa única o decisiva.

Pasemos ahora al proceso de Galileo. La acusación en su contra se basaba, como hemos visto, en su defensa de las tesis copernicanas. En realidad el problema era más sutil, tenía un costado epistemológico: no había habido por parte de la Iglesia una prohibición de usar la astronomía copernicana a los efectos de los cálculos astronómicos, siempre y cuando sólo se le asignara un valor instrumental. Pero Galileo no había respetado según sus acusadores esta restricción. Y no la había respetado no por descuido, sino por un afán deliberado de promover la postura, directamente contraria a lo implicado por pasajes de la Biblia, de que los cielos y la tierra realmente se comportan a la manera copernicana.

Junto a esta interpretación estándar del delito imputado a Galileo, hay, como en el caso de Sócrates, interpretaciones alternativas, tanto religiosas como no religiosas. $\mathrm{Al}$ primer grupo pertenece la formulada por el 
historiador Pietro Redondi ${ }^{6}$, quien ha sostenido que la verdadera imputación era la de que Galileo había en verdad violado nada menos que el dogma de la transubstanciación. De esto Redondi deduce que sus acusadores, al acusar a Galileo de copernicanismo, en realidad le habrían hecho un favor porque si la «verdadera» acusación hubiera sido formalmente planteada difícilmente se hubiera podido sustraer del destino corrido pocos años antes por Giordano Bruno. Pero la tesis de Redondi carece en realidad de evidencias documentales que la sustenten por lo cual, mientras éstas no aparezcan, sólo la podemos tomar a título de interesante conjetura, según han argumentado convincentemente historiadores como R. Westfall o E. Festa. En cuanto a las interpretaciones no religiosas de la acusación a Galileo, sobresale también en este caso la interpretación política. En efecto, Galileo había entrado en fuertes polémicas con sectores poderosos como los jesuitas y los profesores de filosofía. No hacía falta mucho más para atribuirle la intención de subvertir la jerarquía, no sólo de los saberes, sino también de los poderes establecidos. En esta línea interpretativa se considera entonces que la verdadera motivación detrás de la imputación a Galileo no fue la de haber defendido las tesis copernicanas sino la de haber atacado a sectores políticamente poderosos. En otras palabras, la acusación se habría originado no tanto en una cuestión doctrinal sino en cuestiones de poder y autoridad.

Si bien nada desdeñable, esta interpretación política no tiene la fuerza suficiente para desplazar a la interpretación que construye el episodio como un caso de conflicto doctrinal $\mathrm{o}$, más ampliamente, de conflicto entre visiones opuestas del mundo. En este caso también, pues, como en el caso del proceso de Sócrates, la lucha de las interpretaciones y la consiguiente incertidumbre hermenéutica siguen en pie.

Pasemos finalmente al episodio de Josef K. Observemos ante todo que con este caso se produce un giro verdaderamente sorprendente de nuestro problema. En los dos casos anteriores puede dudarse, como hemos visto, acerca de cuál fue la causa real de la acusación pero no puede dudarse de su existencia. En cambio, en este caso nunca se le formuló a $\mathrm{K}$. ninguna acusación, a pesar de lo cual es evidente desde el principio que es considerado culpable. Se rompe así el lazo entre el delito, la culpa y el castigo. Como ha dicho certeramente Milan Kundera, en lugar de haber aquí una falta en busca de una pena hay una pena en busca de su falta.

No obstante la diferencia señalada, igual se ha intentado aplicar aquí las mismas categorías interpretativas aplicadas en los otros casos Existe así una interpretación política del proceso de $\mathrm{K}$, aunque, obviamente, no esgrime el mismo fundamento. Es que, en agudo contraste con Sócrates y Galileo, K. no pretendía cuestionar aspecto alguno del orden establecido. Lo único que aparentemente pretendía era librarse del proceso y retomar su existencia normal de funcionario de banco. Lo que caracteriza a la interpretación política de El Proceso es ver la odisea de K. como una metáfora de la opresión que ejerce un poder impersonal y burocrático sobre el individuo. A la luz de este enfoque, $E l$ Proceso ha sido, por ejemplo, leído en clave weberiana ${ }^{7}$, como una ilustración literaria de la metáfora de la sociedad moderna como una jaula de hierro. Sin embargo, como señalara Marthe Robert refiriéndose no sólo a $E l$ Proceso sino también a $E l$ Castillo, esta lectura política o sociopolítica da más la impresión de escamotear que de resolver la extrema dificultad hermenéutica que presenta la obra: «Todo esto parece sencillo y razonable; pero esta teoría realista y social no agota la difícil problemática de la novela» ${ }^{8}$.

En el otro extremo del arco interpretativo están los intérpretes que sostienen que Kafka sólo quería referirse a procesos psíquicos, en especial los propios. Obras 
como El Proceso o El Castillo aludirían simbólicamente a los mismos problemas que son presentados de manera más claramente psicológica en la Carta al Padre, en diversas anotaciones del Diario y en la correspondencia de Kafka. Dice por ejemplo Bridgwater: «El proceso en el cual los protagonistas de las novelas de Kafka están involucrados es un proceso interno en que los personajes son todos proyecciones o personificaciones de varios aspectos del yo dividido del protagonista» ${ }^{9}$. Y más adelante: «El Proceso ilustra los trabajos de una conciencia culpable y su búsqueda de sí mismo» ${ }^{10}$.

Si bien esta lectura psicológica de $E l$ Proceso suele invocar una rica diversidad de elementos de apoyo, especialmente datos biográficos de su autor ${ }^{11}$, parece igualmente dudoso, como en el caso de la interpretación política, el intento de encasillar la significación de la obra en una sola dimensión. Y lo mismo acontece con otras interpretaciones. Tenemos por ejemplo la clásica interpretación del amigo y albacea de Kafka Max Brod, quien cree ver tanto en El Proceso como en El Castillo una visión religiosa del mundo. Según Brod, Kafka quiso mostrar que sus héroes, en realidad antihéroes, han perdido contacto con lo Indestructible, lo noumenal, $y$, en este sentido, sus historias sugerirían por contraposición la existencia de una realidad trascendente. Específicamente, según Brod, $E l$ Proceso y El Castillo nos presentan las dos formas, la Justicia y la Gracia, bajo las cuales se nos ofrece, según la fuente cabalística en que se habría inspirado Kafka, la divinidad. Más recientemente, en una línea de pensamiento en cierto modo afin a ésta, Kuna ${ }^{12}$ sostiene, sobre la base de un análisis textual, que la detención de Josef $\mathbf{K}$. debe interpretarse como una oportunidad excepcional, reservada a ciertos elegidos, que la Ley le ofrece para que revise su vida y la reorganice poniéndola en contacto con una realidad superior, oportunidad que el personaje de Kafka por cierto desperdicia.
Ahora bien, frente al festival de interpretaciones competitivas en torno de $E l$ Proceso y otras obras de Kafka, hay una corriente de críticos que sostienen la ilegitimidad de todas ellas. Así, por ejemplo, para Beissner ${ }^{13}$, lo mejor que podemos hacer es volver a una pura exégesis de la obra como un texto literario, sin buscarle significaciones externas. Marthe Robert adhiere a esta postura:

«[...] considerar a Kafka como un pensador que disfrazó sus ideas con ropajes novelescos equivale a romper de manera irreparable la unidad de la forma y el contenido que explica la belleza $\mathrm{y}$, más rigurosamente hablando, la verdad de sus relatos» ${ }^{14}$.

Sin embargo, casi a renglón seguido Robert nos dice que es el mismo Kafka quien estimula nuestra necesidad de saber y nos incita a «descubrir qué son el Castillo, el Tribunal, la Ley, la Muralla China, la Colonia Penitenciaria», etc. De esto puede inferirse que, al menos desde un punto de vista filosófico, podemos legítimamente tomar las obras de Kafka por sí mismas, como desafíos a nuestra comprensión del mundo, con independencia de las intenciones que pudo haber tenido su creador.

\section{Refocalizando el debate: la tríada imagen del mundo-forma de vida-sentido}

¿Es posible salir de esta lucha de interpretaciones a través del triunfo definitivo de alguna de ellas? Creemos que no, pero lo que sí podemos hacer es cambiar el foco del debate llevándolo a un terreno distinto al de una lógica de la causalidad. En lugar de poner el foco en la búsqueda de causas $y$ efectos puntuales podemos pasar a una estética del acontecimiento y ponerlo, como se sugirió al comienzo, en la relación mimética, no causal, entre nuestros episodios y su trasfondo, entre el micro- 
cosmos de los procesos judiciales y el macrocosmos de un orden en crisis.

A fin de proveernos de un bagaje conceptual apto para la tarea, consideremos la siguiente tríada: imagen del mundo-forma de vida-sentido. La imagen del mundo representa el costado mental o ideacional de nuestra tríada. La caracterizaremos como el conjunto de supuestos y creencias compartidas en un espacio y tiempo social dado acerca del orden del mundo en sus diversas dimensiones (física, mental, social, metafísica). Toda imagen del mundo es así una entidad compleja que contiene o implica respuestas a preguntas tales como ¿qué clase de entidades pueblan el mundo?, ¿cómo se relacionan entre sí? (dimensión ontológica), ¿cómo lo sabemos?, ¿hasta dónde lo sabemos? (dimensión epistemológica), ¿qué es el bien?, ¿existe el mal absoluto?, ¿qué es una vida buena? (dimensión ética), etc. A su vez, la forma de vida sería el costado social, performativo de la tríada. La definimos como un entramado de prácticas, lingüísticas y no lingüísticas, que los miembros de una comunidad llevan a cabo dentro de un marco compartido de reglas constitutivas de las mismas. Un rasgo también definitorio de toda forma de vida social conocida es que está atravesada por una estructura de poder, o, más exactamente, biopoder, noción foucoultiana que es preciso integrar con la noción wittgensteiniana de forma de vida Finalmente, el sentido de las acciones y los acontecimientos constituye el lado subjetivo de nuestra tríada. El sentido normalmente se apoya en, y a la vez refuerza, la articulación entre la imagen del mundo y la forma de vida. Cuanto más firme sea esta articulación, más segura será la atribución de sentido. Pero si la articulación se debilita, por ejemplo porque las prácticas que constituyen la forma de vida cambian abruptamente o se disgregan y dan paso a la anomia, la atribución de sentido se vuelve problemática y, en el extremo, imposible. La vida humana puede llegar a ser percibida en tales casos a la manera de Macbeth, como «un cuento contado por un idiota, lleno de estruendo y furia, que no significa nada». Las crisis del sentido son obviamente más profundas y generalizadas que las crisis exclusivamente económicas, políticas, etc.

Tenemos delineadas, pues, dos situaciones típico-ideales opuestas. En un extremo, las tres entidades que forman nuestra tríada están perfectamente articuladas entre sí. En el otro extremo, los tres elementos se encuentran en proceso de desarticulación. Volviendo a nuestros episodios, a la luz de este esquema diremos que en los tres casos está presente un trasfondo de derrumbe, o amenaza de derrumbe, de la articulación de la tríada en que se asienta la existencia del antiguo orden. En esta situación, el poder amenazado necesita y procura encontrar, y si no los encuentra inventar, individuos o grupos culpables de propiciar con sus actos, su prédica, o aun con su mera existencia, la disolución del orden. Es a partir de estas condiciones de posibilidad que se han dado nuestros procesos judiciales.

Ahora bien, la supuesta amenaza que el «culpable» representa varía según los casos y da lugar, por ende, como sugerimos al principio, a modos arquetípicos distintos del enfrentamiento entre el Poder y el individuo. Veamos para concluir estas diferencias.

Como suelen afirmar los textos de historia de la filosofía antigua, Sócrates compartió con el movimiento de los sofistas su desinterés por la especulación cosmológica y su "giro» hacia lo humano. Sin embargo, la diferencia reside en que los sofistas fueron funcionales a la satisfacción de necesidades surgidas de la forma de vida de la democracia ateniense pero Sócrates no lo fue. Por el contrario, fue un cuestionador de las instituciones y la forma de vida de sus conciudadanos. Como señalara Calicles, tomar en serio a Sócrates implicaba poner la vida de cada uno, y 
por ende la de la comunidad, «patas para arriba» (Grg. 481 c1-5). En efecto, el diálogo socrático socavaba la tradición al refutar todas las respuestas contenidas en ella a las preguntas morales. Pero Sócrates, a diferencia de lo que haría luego su discípulo Platón, tenía una singularidad: no formulaba nunca, en contraste con lo que se esperaba de un «maestro de virtud», sus propias respuestas a los problemas planteados. Se lo impedía, según afirmaba, su ignorancia, especialmente su falta de conocimiento acerca de «las cosas más grandes». Esta profesión de ignorancia en alguien rodeado de discípulos, unida a un esfuerzo sistemático dirigido a que sus interlocutores reconocieran también su propia ignorancia, era ciertamente uno de los rasgos que hacían de Sócrates un individuo desconcertante. Pero asociado a este énfasis negativo que caracterizaba el diálogo refutatorio socrático o elenjos, también había en el discurso de Sócrates un elemento de carácter exhortativo (protréptico). Es que el autoexamen, el análisis crítico de creencias como vía para el reconocimiento de la propia ignorancia, era para Sócrates condición ineludible para alcanzar la vida buena, una vida que «valiera la pena ser vivida». Cualquier otra preocupación, como las preocupaciones relacionadas con la búsqueda de riquezas, de poder, de reconocimiento, se debía según Sócrates subordinar a ese cuidado de sí mismo, el cuidado de la propia alma. No es por cierto raro que una postura como ésta, profundamente deslegitimadora de valores y prácticas que estaban en la base del orden político, social y moral vigente, haya suscitado hostilidad entre sus contemporáneos. Siguiendo sugerencias de Hegel en sus Lecciones sobre la Historia de la Filosofía y de helenistas contemporáneos como Irwin ${ }^{15}$, podría decirse que detrás del procesamiento $\mathrm{y}$ condena de Sócrates no hay simplemente motivos religiosos o políticos sino la incomensurabilidad derivada de su extrañeza, de la ex-centricidad de su pensamiento y conducta en relación con las formas comunes de pensamiento y conducta de la ciudad. El proceso de Sócrates se nos ofrece así como un ejemplo arquetípico de choque entre un orden y un intelectual «extraño» o «atópico» respecto de ese orden pero a la vez comprometido, con la obsesividad del tábano, en la empresa de perturbarlo.

Nada hay tal vez más contrastante con la extrañeza socrática que la personalidad y el accionar de Galileo. Para empezar, no hay por parte de Galileo ningún desinterés por la competencia entre las imágenes del mundo natural. Por el contrario, Galileo defiende, con notable brillantez y entusiasmo, la teoría copernicana, es decir, una alternativa dentro de esa competencia. $\mathrm{Y}$ más allá de la astronomía copernicana aboga, como lo pone en claro en el Saggiatore $y$ otros lugares, por una sustitución de la vigente imagen aristotélica, cualitativa y teleológica, del mundo natural por una imagen matemática y mecánica. Tampoco hay por cierto un desinterés de Galileo por la política de su tiempo. Se involucra decididamente en los juegos de poder con la esperanza, que se demostraría ilusoria, de inclinar la balanza en favor de sus objetivos. Puede afirmarse, pues, que Galileo intentó una reforma de la imagen del mundo y la forma de vida vigentes desde adentro de sus instituciones, no desde afuera como Sócrates. Por otra parte, se trataba de una reforma importante pero acotada, carente de la radicalidad socrática. No pretendía en absoluto avanzar sobre el área de las creencias religiosas y morales, en las cuales admitía plenamente la autoridad de la Iglesia. Lo que sí pretendía era cambiar lo necesario para hacerle un lugar a la nueva ciencia de modo de asegurar la autonomía de la investigación científica y el respeto hacia sus cultores. La inflexibilidad que mostró la Iglesia romana frente a esta propuesta galileana fue como sabemos extrema, lo cual contribuyó fuertemente al debilitamiento de su poder en el mundo 
moderno, algo que el buen cristiano Galileo no se había propuesto en absoluto lograr. Tenemos, pues, aquí un ejemplo arquetípico de choque también trágico entre la ceguera de un Poder absoluto en su ámbito de influencia, pero sometido a graves amenazas de orden doctrinal y político, y un intelectual que, lejos de pretender derribarlo, le propone aceptar compromisos con los nuevos tiempos, compromisos que, paradójicamente, podrían haberlo beneficiado a la larga.

Finalmente, en el caso de El Proceso nos encontramos, como hemos anticipado, con una situación arquetípica nueva. A partir del comienzo mismo del drama, es decir, del arresto y procesamiento de Josef $K$. sin mención de ninguna acusación en su contra, se percibe la pérdida de un mundo racionalmente ordenado, aunque no sea más que de un modo parcial. La extrañeza no caracteriza ya sólo a un individuo en su relación con un orden establecido, sino que invade toda la realidad. Cae con ello el supuesto de la inteligibilidad del mundo, tradicionalmente garantizada ya sea por la voluntad divina, ya sea por una legalidad inmanente e inquebrantable, ya sea por ambas cosas a la vez. En este sentido $K$. se enfrenta con un mundo que, para usar palabras del mismo Kafka, «ha dejado de ser un hogar para el hombre». No existe, pues, aquí, como en el caso de Galileo, una imagen de un mundo ordenado que se opone a otra imagen de un mundo ordenado de una manera distinta, ni tampoco, como en el caso de Sócrates, un diálogo dirigido a establecer los fundamentos racionales de la moralidad. Lo que hay ahora es la pura destrucción del orden sin contrapartida o escape alguno. Posner ha descrito la naturaleza de este mundo de un modo certero:

«El corazón de El Proceso reside en los esfuerzos fútiles de $\mathrm{K}$. por encontrar un significado humano en el universo, simbolizado por la Corte, que no ha sido creado para acomodarse o ser inteligible al hombre sino que es arbitrario, impersonal, cruel, engañoso y elusivo» ${ }^{16}$.

Se trata de un mundo que no ofrece escape para nuestro personaje. $Y$ no hay escape porque en El Proceso, junto a la pérdida de la imagen de un orden racional del mundo y la desorganización de la forma de vida, hay una disolución del sujeto mismo. $\mathrm{K}$. ha perdido, en agudo contraste con Sócrates y Galileo, toda capacidad de ser un agente. Está a merced de fuerzas que traen consigo no sólo graves amenazas, en el extremo la muerte, sino sobre todo un castigo de una naturaleza novedosa: la degradación y pérdida de la humanidad en el hombre, es decir, su degradación ontológica. Así pues, el proceso de Josef $\mathrm{K}$. es un ejemplo arquetípico del proceso de destrucción lenta pero inexorable de la humanidad de un individuo al cual, paradójicamente, no es necesario imputarle delito alguno. Su crimen reside simplemente, en términos de Spinoza, en el puro deseo de perseverar en su ser.

En conclusión, hemos descrito someramente, a partir de una estética del acontecimiento, tres casos de enfrentamiento entre el individuo y el Poder. El carácter arquetípico que les hemos atribuido implica que no pertenecen tan sólo al dominio de la historia o de la literatura, sino también al de una filosofía del presente.
1 Quisiera agradecer al Instituto de Filosofía del CSIC y en particular a su Director, profesor José M. González García, por su amable invitación a visi- tar el Instituto durante el primer semestre de 2003, oportunidad en que pude dedicarme plenamente a investigar los temas de este ensayo. 
2 Sin pretender entrar aquí en el llamado «problema de Sócrates», puede afirmarse que existe un amplio consenso en que la Apología platónica, aunque no sea fiel a la letra del discurso pronunciado por Sócrates en su defensa, sí lo es en relación con su contenido.

3 Un ejemplo claro en este sentido lo proporcion I. F. Stone, The Trial of Socrates, Nueva York, 1989.

4 Oración fúnebre de Pericles (Tucídides, 2.40 $1-2)$.

5 Una de las obras más representativas de esta interpretación es sin duda T. C. Brickhouse y N. D. Smith, Socrates on Trial, Princeton, 1989.

${ }^{6}$ P. Redondi, Galileo Eretico, Turín, 1983.

$7 \mathrm{Cf}$., entre otras obras representativas de este enfoque, P. Eisner, Franz Kafka and Prague, Nueva
York, 1950; J. M. González García, La Máquina Burocrática, Madrid, 1989, etc.

${ }^{8}$ M. Robert, Lo Viejo y lo Nuevo, Caracas, 1992, p. 21

9 P. Bridgwater, Kafka and Nietzsche, Bonn, 1974 p. 60 .

10 P. Bridgwater, op. cit., p. 67.

II Un intento excelente dentro de este enfoque es E. Canetti, El otro Proceso de Kafka, Madrid, 1983. 12 F. Kuna, On Kafka, Londres, 1976.

13 F. Beissner, Der Erzähler Franz Kafka, Stuttgart, 1952.

${ }_{14}$ M. Robert, op. cit., p. 220

15 T. Irwin, Classical Thought, Nueva York, 1989 p. 84.

${ }^{16}$ R. Posner, Law and Literature, Cambridge, 1998, p. 135. 